\title{
Incentive Contract Study on the Design Optimization and Innovation of Green Buildings: A Perspective of Value Chain
}

\author{
Ling Shen ${ }^{*}$ and Z.H. Wang
}

HOHAI University, HHU. Nanjing, China

\begin{abstract}
The optimization and innovation of design play a crucial part in increasing the whole merit of the value chain of green building. As major proprietors passing on the value of green building, architecture developers should motivate design enterprises to enhance their level of working effort through contract planning. The Stakelberg game model is applied in this paper, and the approach to determine the income/cost sharing coefficient of optimization $\&$ innovation is explored, which is a key parameter of incentive contract. The study reveals that architecture developers determine the income sharing coefficient not only by the design enterprises' level of effort, but the achievements in "benchmark green buildings"; after the income sharing coefficient $r^{*}$ are confirmed, the optimum cost sharing coefficient $t^{*}$ is then obtained, which is $t^{*}=\frac{2-3 r}{2-r}$, with $0<r<\frac{2}{3}$. The research results provide theoretical references and methodological routes for architecture developers to design incentive contracts.
\end{abstract}

Keywords: Green building, design optimization and innovation, Value Chain, incentive contract, income sharing coefficient, cost sharing coefficient.

\section{INTRODUCTION}

Design optimization and innovation (DOI) is of vital significance to reducing the life-cycle cost and enhancing the value of green buildings. However, the designs of architectures in China mainly adopt the fixed reward pattern charging for a long period, which charges according to the investment proportion or unit construction area index, regardless of the connection between the income of design enterprises, risk, industry and the overall income of product value chain. As a result, design enterprises fail to gain the pressure and motivation to optimize the products designed from a life-cycle perspective.

The research "Study on the Economics of Green Buildings in China" was undertaken jointly by the Center of Science and Technology of Construction, Ministry of Housing and Urban-Rural Construction, and the center of Planning and Design, Peking University indicates that:

1) At present, either residential or public green buildings in China can hardly reach to the incremental cost of the same Star-evaluation criteria, shown in Figs. (1, 2). Although it may lie in various understandings of the concept of "incremental cost" and calculation scope, and the inconsistency among different market orientations, the fact that design enterprises fail to analyze and optimize the design program and technology of green buildings and the selection of materials also accounts for the discrepancy [1].

*Address correspondence to this author at the HOHAI University, HHU. Nanjing, China; Tel: 025-847-33199; Fax: 025-84733199;

E-mail: s17455@sina.com
Statistics show that there is a huge optimization room for the incremental cost of green buildings in China.

2) From the aspects of improving both the technology content and the economic and environmental value, there is a huge room for the optimization of technological measures taken by green buildings participating in evaluation.

In addition, the to-be-issued Evaluation Standard for Green Building (latest edition) also encourages technological innovation and promotion by adding the term of innovation. Therefore, it is an inevitable choice for improving the whole merit of the value chain and promoting the sound and rapid development of the industry and products of green building, by studying the incentive mechanism of the DOI of green buildings from the angle of value chain, and advancing design enterprises to optimize and innovate design products from the angle of building incremental cost, even life-cycle cost.

\section{THE COMPOSITION OF GREEN BUILDING VALUE CHAIN, THE STATUS OF DESIGN ENTERPRISES IN THE CHAIN AND ITS BEHAVIOR CHARACTERISTICS ANALYSIS}

\subsection{The Composition and Characteristics of Green Building Value Chain}

Theoretical researches of value chain have extended from enterprises to industries and products in the last three decades. An industrial value chain is a physical set of relevant enterprises involved in the whole process of producing goods (and services), and also a systematic method and effective tool for tracking the process of value 


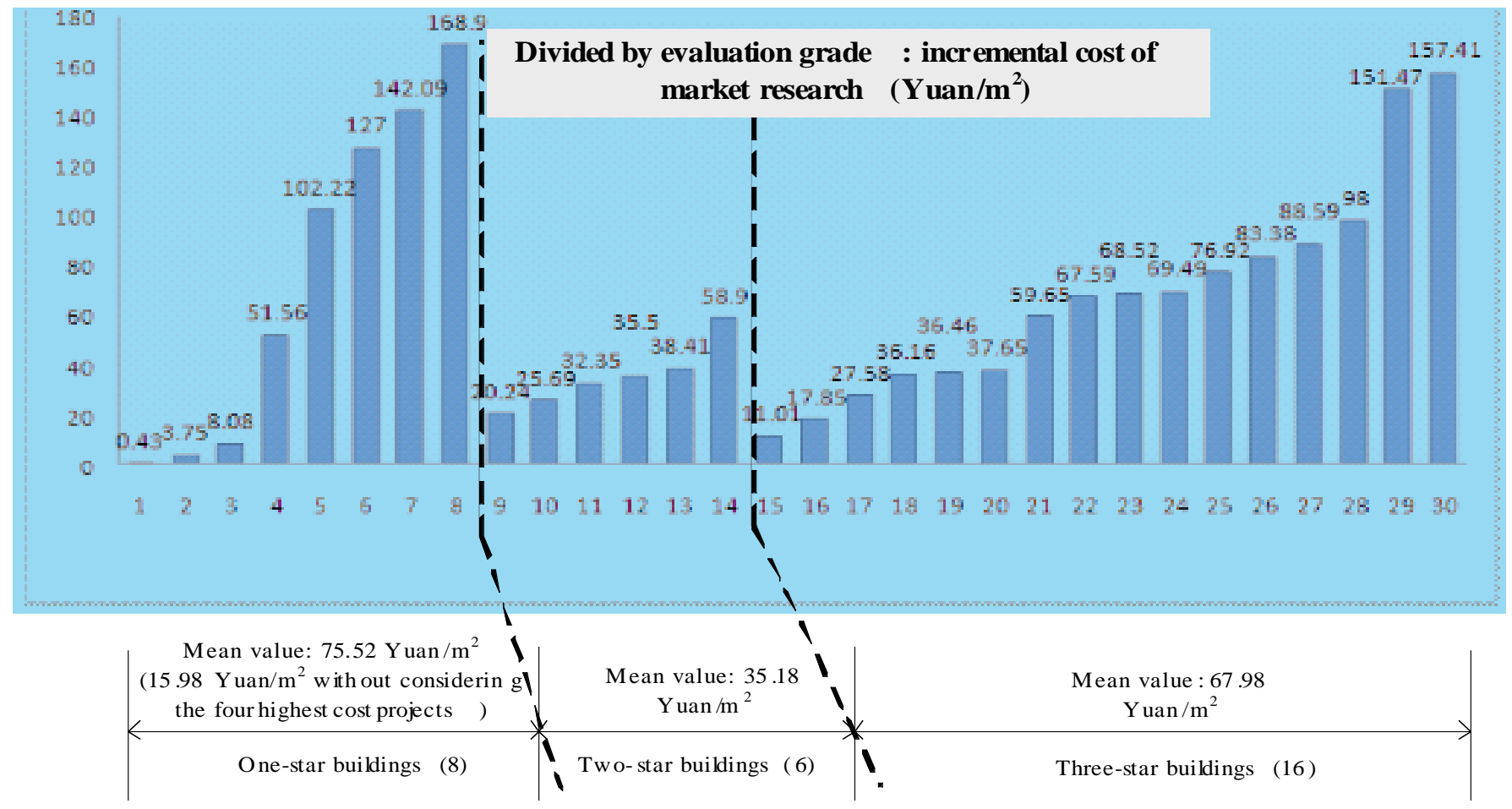

Fig. (1). Comparison between the incremental costs of residential buildings.

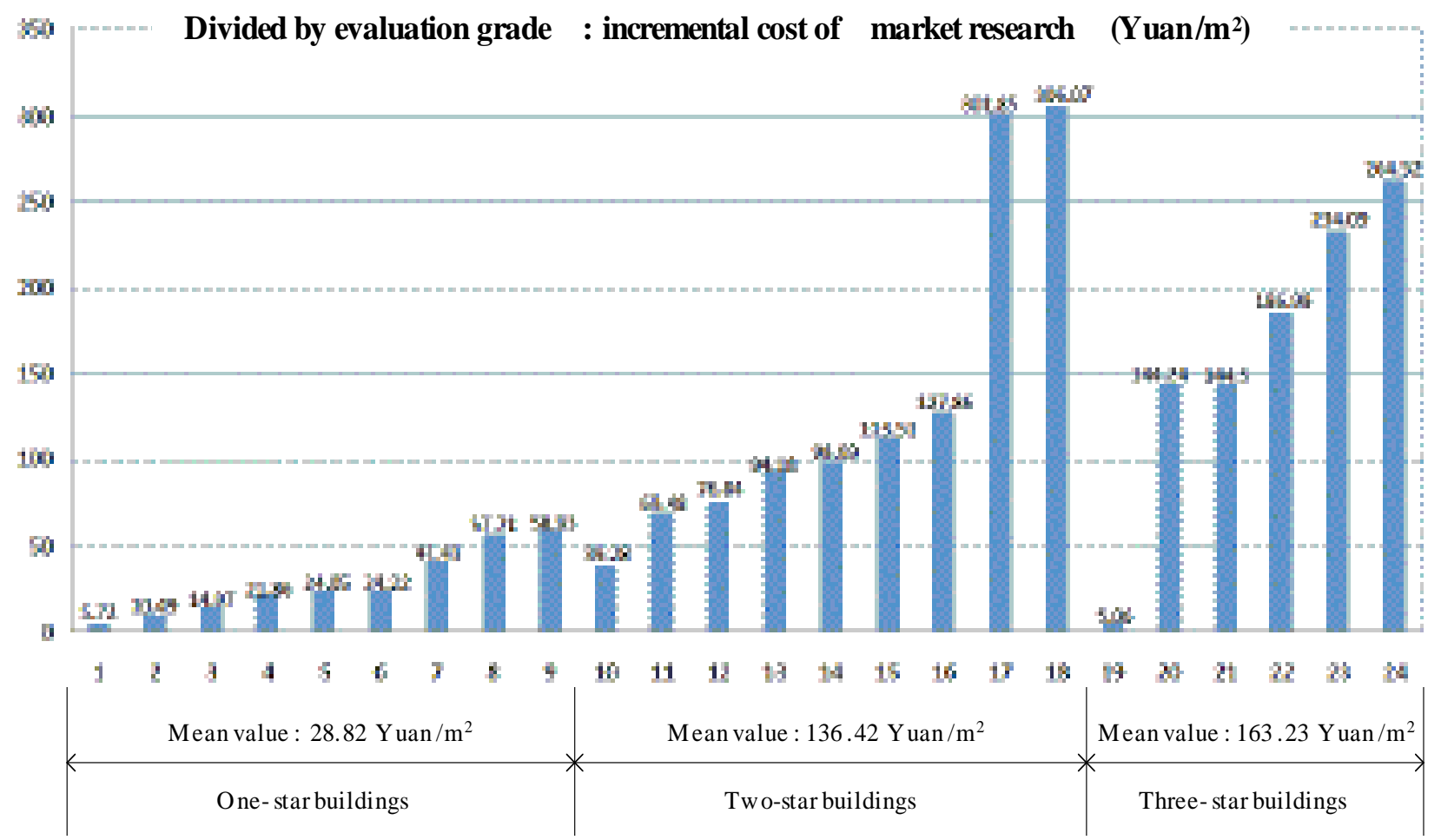

Fig. (2). Comparison between the incremental costs of public buildings (Source: Ye Zuda. Study on the Economics of Green Buildings in China. China Architecture \& Building Press, 2013).

creation, distribution and transmission of the aggregation as a whole, and then analyzing its advantages in competition [2]; while product value chain mainly focuses on the forming process of products' function and value-in-use, dividing value-added stages in terms of the life-cycle of products [3].
The analytical thinking on the value chain of industry and product is developed and applied into green buildings in this paper. Combined with the life-cycle characteristics of green buildings, its value chain is defined as an organic set representing the value-added process, which consists of three major interdependent stages within the whole life-cycle: 


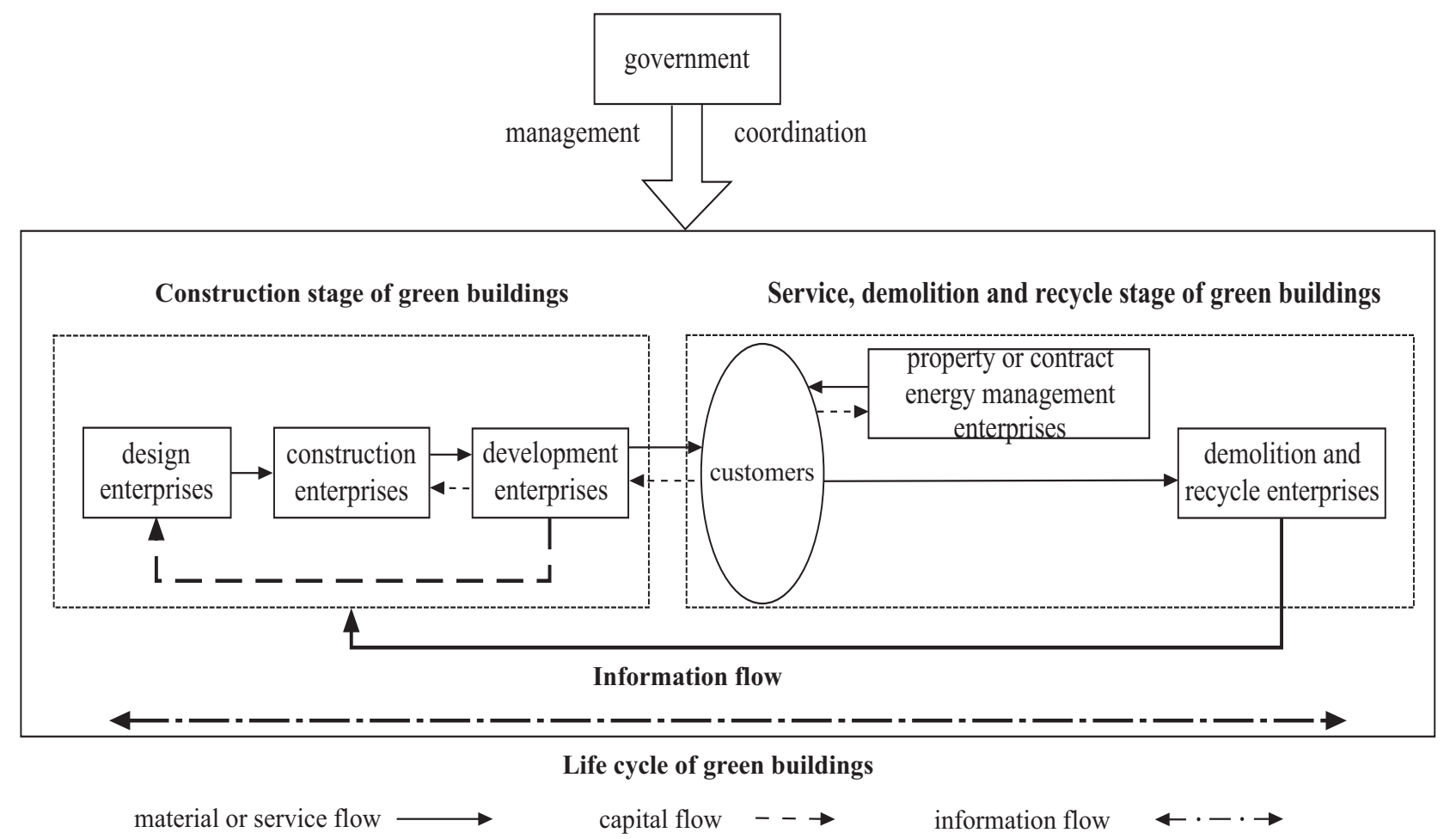

Fig. (3). Basic formation of green building value chain.

producing stage - enterprises of development, design and construction; service stage - consumers and contract energy management enterprises; ending stage of life-cycle demolition and recycle enterprises, shown in Fig. (3).

Compared with general buildings, there are two distinctive properties in the value chain of green building:

1) The value chain is formed in annularity or network, having remarkable external overflow effect.

Green building has changed the one-way value chain form of "resource - product - waste" of general buildings. By using renewable materials and energy, and harmless treatment of the waste, it establishes a positive and interactive material development relationship between nature, society and environment. The value chain consists of market value chain and environment value chain, in the form of annularity or network [4]. Because of the existence of the environment value chain of green buildings, the subject of market cannot enjoy the whole output of its investment. As a result, the remarkable external overflow effect reflects in green buildings [5].

2) Several behavior subjects are found in the value chain, resulting in difficulties in coordination.

Green building value chain consists of a certain number of individual members. Although constrained by "chain hosts" (development enterprises) or contracts, the formation of industrial value chain mainly is "strategy alliance" or "industrial cluster", of which strategy alliance is congenitally weakrestricted, industrial cluster much weaker. As a result, high coordination similar to enterprises' is hard to reach to among each node in the industry [6]. Furthermore, the interval between investing incremental cost of green buildings and realizing increase-in-value is relatively longer, whose longterm increase-in-value is hard to be comprehensively and precisely quantified. Uncertainty and risk also exist in the increase-in-value and incremental cost themselves. Therefore, proper excitation and constraint mechanism should be studied to achieve the harmonious symbiosis between value chains.

\subsection{The Status of Design Enterprises in the Value Chain and its Behavior Characteristics}

Both theoretical and empirical studies reach a consensus that design is the most crucial part deciding the life-cycle cost of building products. The quality of design and the standard of DOI not only influence the cost of green buildings, but the cost of daily maintenance, overhaul and part of update during their service warranty [7, 8]. As the comprehensive carrier of new materials (devices and facilities), new technologies, and new technicstechniques, green building is with features of hi-tech products, requiring a better DOI standard in the design stage, in order to achieve the optimum life-cycle cost and increase-in-value of the whole value chain of green buildings. Therefore, design enterprises take on essential position in the value chain of green buildings, and play a decisive role in enhancing the value.

In the value chain of green buildings, design enterprises are not the initiators and core firms, but are acceptors who undertake design works consigned by developers. With zero 
motivation, the design will only be carried out according to the proxy and state compulsory standards and criteria. In the view of interests, the behavior is neutral, and also passive to the promotion of green buildings. Only when the incremental cost of DOI is compensated and the value of knowledge is achieved, design enterprises will show their initiative accordingly.

\section{INCENTIVE SUBJECTS OF GREEN BUILDINGS' DOI AND THE INCENTIVE REALIZATION MECHANISM}

\subsection{Incentive Subjects of Green Buildings}

The incentive subjects in the theory of Principal-agent mainly are consignors. As core developers, consumers and government in the value chain jointly decide the level of demand for DOI of green buildings, they all can be incentive subjects. The main motivations of consumers, developers and government are respectively - to reduce the life-cycle cost, especially the using cost directly undertaken by consumers; to attain the extra profit brought by raising selling price; and to achieve increase-in-value of environmental and social values. Therefore, the beneficial subject of green building's DOI should likewise be the incentive subject of optimization and innovation.

\subsection{Realization Mechanism of Various Incentive Subjects and their Correlations}

\subsubsection{Realization Mechanism of Various Incentive Subjects}

Consumer incentive mechanism - market mechanism

As the nodes help to achieve the increase-in-value of the value chain, consumers influence the enterprises' investment decisions through market price. If the value-added green buildings after DOI are sold in reasonable and fair prices, then the value of the measures will be realized. Such a benign cycle is formed gradually, the value chain of green buildings being promoted sustainably. Nevertheless, the consumers' desire to purchase and utilize the buildings is determined by their capacity and willing for paying. If finance permitted, their willing for paying mainly derives from the anticipation for the reduction of green buildings' life-cycle cost (especially service-period cost), and the improvement of quality of life. Obviously, the green buildings after DOI will be accepted only if the related information is known and trusted by consumers. Otherwise, the buildings will unlikely be accepted by the market due to their high price.

2) Government incentive mechanism - policy mechanism

The economic externality of green building has determined that, the market's sustainable development is largely dependent on the incremental cost payers of green buildings and their DOI being given certain economic encouragement by the government. According to the theory of Public Choice, being economic man, government itself pursues the maximization of benefit as well, so it should select the objects and degree of incentive properly. Current studies show that: although consumers more than developers are the main force of external cost of the industry, demand-side incentive lacks implementation conditions and maneuverability, the incentive effect also being hard to control [9]. Therefore, during the pre-development period of green buildings, government should determine an appropriate incentive degree in terms of the promotion objectives, market price and financial situation of green buildings, and motivate design enterprises indirectly by impelling developers with economic measures of reward and allowance.

3) Developer incentive mechanism - contract mechanism

Architecture developers are the sponsors and organizers of green buildings' construction and DOI. They serve the increment of value and distribute value by connecting the enterprises' materials and value flows of industries upstream and downstream [10]. The initiative of developers' willing to organize DOI derives from the extra profit of the market after the optimization of green buildings, rewards and allowances of the government, and other incentive measures of economic preferential policy. Only when the total profit (market + policy) of green buildings after DOI is no less than that of green buildings before DOI, developers will consciously choose to organize the DOI of green buildings, and motivate design enterprises through proper contract planning.

\subsubsection{Correlation Between Mechanisms of Various Incentive Subjects}

The principles of the increase-in-value of value chain and sustainable development indicate that: the combination of market price incentive mechanisms of consumers as bases and policy incentive mechanisms of government as adjustment and supplementary supports the successful operation of the contract mechanism between developers and design enterprises. The correlation between them is shown in Fig. (4).

To sum up, developers are the direct incentive subject of DOI and investment decision from the perspective of green building value chain, guided by incentive policies of the government and influenced by the purchase demand of consumers, playing a vital role of inheritance and connection in the value chain. Since developers and design enterprises are connected through contract agreements in the green building value chain, the incentive for design enterprises should be achieved through contract planning.

\section{INCENTIVE CONTRACT PLANNING OF DESIGN ENTERPRISES FOR GREEN BUILDINGS' DOI}

\subsection{Influence Factors of DOI's Incentive Contract and Basic Ideas of Compact Design}

\subsubsection{Influence Factors of Incentive Contract}

Asymmetric information can be divided into exogenous and endogenous asymmetric two categories in the 


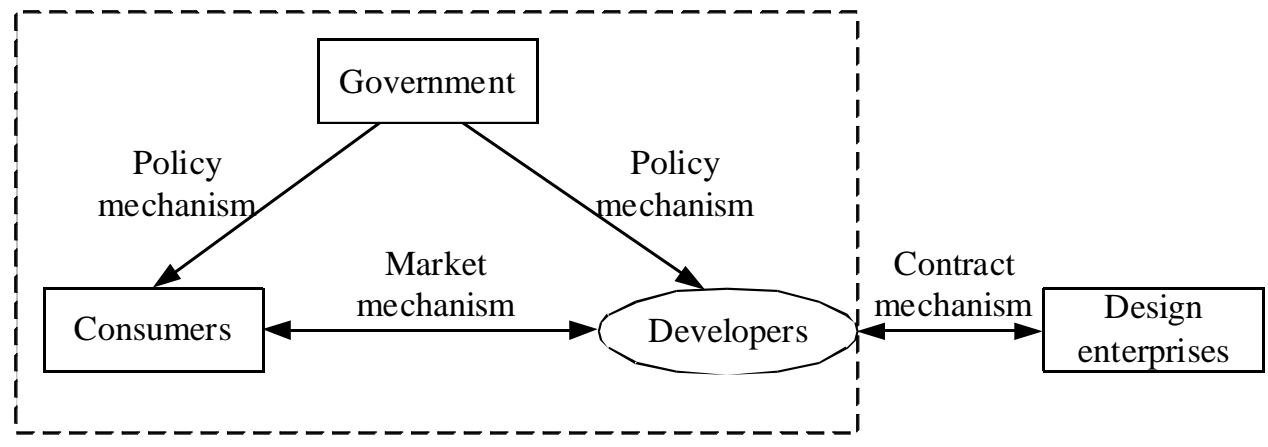

Fig. (4). Correlation within the incentive mechanism operation of the DOI of green buildings.

information economics. Exogenous asymmetric refers to the partnership that already existed before the partnership, the inherent characteristics and nature of the behavior factors of information, such as enterprise's work quality, staff quality, cost and so on, this kind of information can be abstracted as member's contribution to the value chain and cost coefficient. Endogenous asymmetry means the consequence appears after the partnership existed. It usually happens due to the "moral hazard" of members, such as working hard, laziness, etc. The consequences of this kind of information can be abstracted as a member of the work effort [11]. In order to analyze the asymmetric information factors that have been applied in incentive contract design research, the author search the literature in $\mathrm{CNKI}$ (Chinese National Knowledge Infrastructure ) on August 9, 2013. The specific process is as follows: search range: social science, retrieval period: 2000-2013. When "income distribution" and "working effort" were typed, 1410 papers were showed. In the same way, 811 and 21 papers were brought up when "income distribution" \& "Work contribution coefficient", "income distribution" \& "observable reference variables" were input. Two representative articles were selected; Tang qi (2002) considered the influence of effort and lazy level of leaguer enterprises, partners' pressure and subjective mistakes, leaguer enterprises risk aversion, group penalties on the contract in the study of virtual enterprise income distribution [12]. Lu Jihua, etc. (2003) considered the impact of the work effort level, contribute to the work factor, innovation costs, the cost of risk on income distribution contract [13]. Green building value chain has its unique technical and economic characteristics, but the main factors that influence the incentive contract are the same as the general value chain incentive contracts in essence, namely the development enterprise make decision about fixed amount and floating compensation ratio based on principalagent incentive model, the design enterprise's hard working level and its marginal revenue, the observable reference variables, should be the main influence factors of incentive contract design.

\subsubsection{Basic Idea of Incentive Contract Design}

The main duty of design enterprises is to implement the design of green buildings, plan comparison and innovation (optimization and innovation). The core of incentive contract planning is to motivate design enterprises to improve their level of working effort, through income/cost sharing mechanism of value chain. Under asymmetric information, developers are unable to observe the specific activities undertaken by design enterprises. In order to reduce the loss of developers and the value chain, similar and same-star "Benchmark green building" (the data can be obtained from local green building center or other departments in practice) index as an observable reference variable is introduced in the design of incentive contract model, and relevant performances are compared in order to determine the value of DOI more properly while eliminating the influences of uncertain factors. The contract model is divided into two stages to analyze in this paper: the first stage, income sharing model is established to determine the DOI income sharing coefficient; the second stage, cost sharing model is established to determine the DOI cost sharing coefficient.

\subsection{DOI Income Sharing Model}

\subsubsection{Model Assumption}

Assumption 1: the level of design enterprise's working effort is $a$, and the increase-in-value of green buildings brought by DOI is related with $a$. Let $i$ stand for the marginal revenue of design enterprises' level of working effort (effort level $a$ transforming into real revenue - a transformation constant of price rising and government's allowance acquisition), then relationship between the value chain income $\pi$ created from DOI and the level of working effort $a$ is $[14,15]$ :

$\pi=i a+\theta$

where $\theta$ is the environment random disturb variable, following normal distribution $\mathrm{N}\left(0, \sigma^{2}\right)$.

The level of working effort determines its mean output value or anticipated profit, but the output variance - external uncertainty is unable to be affected. Therefore, $\mathrm{E}(\pi)=i a$, $\operatorname{Var}(\pi)=\sigma^{2}$.

Assumption 2: the achievement after DOI of similar and same-star "Benchmark green building" in the research area is $\pi_{1}$, which is unrelated to design enterprises' level of working effort $a$, yet might be related to external variable $\theta$, then related to of $\pi$ design enterprises. Let $\pi_{1}$ obeying normal distribution, mean value is 0 , variance is $\sigma^{2}$. If the incentive for design enterprises consists of fixed reward $\alpha$ and income share, and is linear, then the incentive contract of developers is $[15,16]$ :

$\mathrm{s}\left(\pi, \pi_{1}\right)=\alpha+r\left(\pi+\gamma \pi_{1}\right)$ 
where $r$ is the degree of incentive - income sharing coefficient, $\gamma$ is the relationship between design enterprises' income and $\pi_{1}$. Then the job of developers is to select proper $\alpha, r$ and $\gamma$, to achieve the optimization of incentive contract.

Assumption 3: developers are risk-neural, while design enterprises are risk-averse. The incremental income sharing coefficient $r$ is constrained by $0 \leq r \leq 1$. Obviously, design enterprises take no risks when $r=0$; they have to undertake all risks when $r=1$. Let the utility function of design enterprises have the property of constant absolute-riskaversion, $\rho$ is absolute risk aversion, $\omega$ is the actual income of design enterprises' DOI, then $\mathrm{u}=-\mathrm{e}^{-\rho \omega}$. [14].

Assumption 4: the level of design enterprises' working effort is $a$, which is related to the DOI cost. Let the DOI cost coefficient be $b(0 \leq b \leq 1)$, then its effort cost is $c(a)=\frac{1}{2} b a$ ${ }^{2}[17]$

\subsubsection{Model Establishment}

1) Determination of developers' utility function

The developers' utility function can be expressed as $\mathrm{v}\left(\pi-\mathrm{s}\left(\pi, \pi_{1}\right)\right)$.

According to the assumption that developers are riskneural, the anticipated utility of developers is equal to the anticipated income:

$\mathrm{E}\left(\pi-\alpha-r\left(\pi+\gamma \pi_{1}\right)\right)=-\alpha+(1-r) a$

2) Determination of design enterprises' utility function

The design enterprises' utility function can be expressed as $\mathrm{u}\left(\mathrm{s}\left(\pi, \pi_{1}\right)\right)-\mathrm{c}(a)$;

According to the assumption that design enterprises are risk-averse, the actual incentive income of design enterprises is:

$$
\begin{aligned}
& \omega=\mathrm{s}\left(\pi, \pi_{1}\right)-c(a) \\
& =\alpha+r\left(\pi+\gamma \pi_{1}\right)-\frac{1}{2} b a^{2} \\
& =\alpha+r\left(\mathrm{i} a+\theta+\gamma \pi_{1}\right)-\frac{1}{2} b a^{2}
\end{aligned}
$$

Let the anticipated utility of design enterprises be:

$\mathrm{Eu}=-\mathrm{E}\left(\mathrm{e}^{-\rho \omega}\right)=-\mathrm{e}^{-\rho\left(E \omega-\frac{1}{2} \rho \operatorname{Var}(\omega)\right)}$

According to the definition of Certainty Equivalent Wealth - that if the agent is risk-averse, the certainty equivalence equals to the mean value of random income subtracting risk cost, it can be seen that $\mathrm{Eu}=$ $\mathrm{u}(\mathrm{CE})$, thus the certainty equivalence income of design enterprises $\mathrm{CE}$ being:

$$
\begin{aligned}
\mathrm{CE} & =\mathrm{E}(\omega)-\frac{1}{2} \rho r^{2} \operatorname{Var}\left(\pi+\gamma \pi_{1}\right) \\
& =\alpha+\mathrm{i} r a-\frac{1}{2} \rho r^{2}\left(\sigma^{2}+\gamma^{2} \sigma^{2}{ }_{1}+2 \gamma \operatorname{Cov}\left(\pi, \pi_{1}\right)\right)-\frac{1}{2} b a^{2}
\end{aligned}
$$

where $E(\omega)$ stands for the anticipated income of design enterprises, $\frac{1}{2} \rho r^{2} \operatorname{Var}\left(\pi+\gamma \pi_{1}\right)$ the risk cost and $\operatorname{Cov}\left(\pi, \pi_{1}\right)$ the covariance between $\pi$ and $\pi_{1}$.

When $r=0$, the risk cost of design enterprises is 0 . The maximum anticipated utility function $\mathrm{Eu}=-\mathrm{E}\left(\mathrm{e}^{-\rho \omega}\right)$ is equal to the maximization of the above-mentioned certainty equivalence income.

Let $\varpi$ be the reserved income level, if the certainty equivalence income is less than $\bar{\sigma}$, then design enterprises will not accept the incentive contract. So the participation constraint of design enterprises is:

$$
\alpha+\operatorname{ir} a-\frac{1}{2} \rho r^{2}\left(\sigma^{2}+\gamma^{2} \sigma^{2}{ }_{1}+2 \gamma \operatorname{Cov}\left(\pi, \pi_{1}\right)\right)-\frac{1}{2} b a^{2} \geq \varpi
$$

3) Incentive contract model

As the sponsors and organizers of DOI, developers lead the whole game process. Design enterprises can select their level of working effort $a$ according to contract conditions $\alpha, \beta$ and $\gamma$ proposed by developers. Therefore, the influence of contract conditions on design enterprises' $a$ should be taken into consideration in order to achieve the maximization of the anticipated utility, then the object function of income sharing model is built. If design enterprises are expected to select the level of working effort $a$ that developers desire, the design of incentive function is bound to meet the condition that the utility gain from the selection of $a$ is greater than utilities gain from other effort level $a^{\prime}$ - the condition is also called Incentive Compatibility constraint (IC) of design enterprises. In addition, the utility that design enterprises gain from developers' incentive contract should not be less than the reserved utility $\varpi$ the condition is called Individual Rationality constraint (IR).

Based on the above hypothesis and analysis, the income sharing incentive contract model of design enterprises from developers is:

Objective function:

$$
\begin{array}{r}
\operatorname{maxEV}=-\alpha+(1-r) a \\
\text { s.t.(IR) }
\end{array}
$$

$\alpha+\mathrm{i} r a-\frac{1}{2} \rho r^{2}\left(\sigma^{2}+\gamma^{2} \sigma^{2}{ }_{1}+2 \gamma \operatorname{Cov}\left(\pi, \pi_{1}\right)\right)-\frac{1}{2} b a^{2} \geq \varpi$

$\alpha+\operatorname{ir} a-1 / 2 \rho r^{2}\left(\sigma^{2}+\gamma^{2} \sigma^{2}{ }_{1}+2 \gamma \operatorname{Cov}\left(\pi, \pi_{1}\right)\right)-\frac{1}{2} b a^{2} \geq$

$\alpha+\operatorname{ir} a^{\prime}-1 / 2 \rho r^{2}\left(\sigma^{2}+\gamma^{2} \sigma^{2}{ }_{1}+2 \gamma \operatorname{Cov}\left(\pi, \pi_{1}\right)\right)-\frac{1}{2} b \alpha^{\prime 2}$

any $a^{\prime} \in \mathrm{A}$ 


\subsubsection{Model Solving and Analysis}

For any incentive contract $s\left(\pi, \pi_{1}\right)$ given by developers, design enterprises should select a proper $a$ to maximize its anticipated utility, where the first order condition of maximization is

$a=\frac{i r}{b}$

The anticipated income is:

$\mathrm{E}\left(\pi-\alpha-r\left(\pi+\gamma \pi_{1}\right)\right)=-\alpha+(1-r) a$

Since $\mathrm{E}\left(\pi_{1}\right)=0$, substitute participation constraint and incentive compatibility constraint into the equation, then the optimization issue of developers is turned into:

$$
\begin{gathered}
\operatorname{Max}_{\mathrm{r}, \gamma} \frac{i^{2} r}{b}-\frac{1}{2} \rho r^{2}\left(\sigma^{2}+\gamma^{2} \sigma^{2}{ }_{1}+2 \gamma \operatorname{Cov}\left(\pi, \pi_{1}\right)\right)- \\
\left(\frac{1}{2 b}\right) \mathrm{i}^{2} r^{2}-\varpi
\end{gathered}
$$

The first order condition of the above problem is:

$$
\begin{aligned}
& \frac{i^{2}}{b}-\rho r\left(\sigma^{2}+\gamma^{2} \sigma^{2}{ }_{1}+2 \gamma \operatorname{Cov}\left(\pi, \pi_{1}\right)\right)-\frac{1}{b} \mathrm{i}^{2} r=0 \\
& \gamma^{2} \sigma_{1}+\operatorname{Cov}\left(\pi, \pi_{1}\right)=0
\end{aligned}
$$

The optimum condition is solved as:

$$
\begin{aligned}
& r^{*}=\mathrm{i}^{2} /\left[\mathrm{i}^{2}+\rho b\left(\sigma^{2}-\frac{\operatorname{Cov}^{2}\left(\pi, \pi_{1}\right)}{\sigma_{1}^{2}}\right)\right] \\
& \gamma^{*}=-\frac{\operatorname{Cov}\left(\pi, \pi_{1}\right)}{\sigma_{1}^{2}}
\end{aligned}
$$

Developers should reasonably determine income sharing coefficient, not only according to the design enterprises' effort level, but the achievements in "benchmark green buildings" of the market. If the working achievements are higher than that of "benchmark green buildings", income sharing coefficient $\beta$ should be raised accordingly; otherwise it should be turned down to advance the degree of working effort. In that way, the whole value of the value chain is improved.

\subsection{DOI Cost Sharing Model}

\subsubsection{Model Assumption}

Risk sharing has remarkable positive influence on the income sharing contract. The share of DOI cost of design enterprises is considered when planning incentive contract, in order to further improve the enthusiasm of design enterprises.

Assumption 1: If the DOI of design enterprises is accomplished, then certain DOI income share and cost allowance will be given by developers. Let the DOI income sharing coefficient be $r$ (same to the above, which is a known condition in this model), the DOI cost sharing coefficient be $t(0 \leq t \leq 1)$;

Assumption 2: Since the model only concerns about the DOI sharing problem, the variable cost only consider the
DOI cost $c(a)=\frac{1}{2} b a^{2}$ of design enterprises, and the other costs are all set constant $[16,18]$;

\subsubsection{Model Establishment and Analysis}

Value chain income of the first stage's DOI:

$\pi=i a+\theta$

DOI profit design enterprises achieve:

$\mathrm{r}\left(\pi_{\mathrm{d}}\right)=r \pi-\frac{1}{2} b a^{2}(1-\mathrm{t})$

DOI profit developers achieve:

$\mathrm{r}\left(\pi_{\mathrm{h}}\right)=(1-r) \pi-\frac{1}{2} b a^{2} \mathrm{t}$

Profit of value chain optimization and innovation:

$\mathrm{r}(\pi)=\pi-\frac{1}{2} b a^{2}$

where $\theta$ stands for the environment random disturb variable, following normal distribution $\mathrm{N}\left(0, \sigma^{2}\right)$.

1) Determination of the design enterprises' level of working effort

The method of Inverse Deducing in the game theory is applied. Firstly, assume the DOI income sharing coefficient $r$ and cost sharing coefficient $t$ is already known. In practice, it is developers who propose contract conditions at first, then design enterprises determine their effort level $a$ in terms of the degree of incentive, which is a non-cooperative game process.

The first order conditions are determined by (11) and (12):

$a=\frac{i r}{(1-t) b}$

Since both $\partial a / \partial t$ and $\partial a / \partial r$ are bigger than 0 , the design enterprises' level of working effort $a$ and the incremental income sharing coefficient $r$ and cost sharing coefficient $t$ are positively correlated, namely the bigger both coefficients are, the level of working effort is higher; otherwise the level is lower.

2) Adjustments in optimum incremental cost sharing coefficient and level of working effort

When DOI income sharing coefficient $r$ of the first stage is determined, substitute (15) into (13), then

$t^{*}=\frac{2-3 r}{2-r}$

Obviously, if the incremental income sharing coefficient $r$ is given, the equilibrium solution to the non-cooperative game between developer and design enterprises is

$\mathrm{N}\left(t^{*}, a^{*}\right)=\left|\left(\mathrm{t}^{*}, a^{*}\right)\right| \frac{2-3 r}{2-r}, \frac{(2-r) i}{2 b} \mid$. 
Under non-cooperative game, the optimum DOI cost sharing coefficient $t^{*}$ is $\frac{2-3 r}{2-r}$ without considering the maximization of the value chain's whole benefit. At the meantime, the DOI incremental income sharing coefficient $\mathrm{r}$ is limited by $0<\mathrm{r}<\frac{2}{3}$.

Substitute $a^{*}=\frac{(2-r) i}{2 b}$ into the former equation, we get:

$\pi^{*}=\mathrm{i} \frac{(2-r) i}{2 b}+\theta$

$r\left(\pi_{\mathrm{d}}^{*}\right)=\mathrm{r} \pi^{*}-\frac{1}{2} \frac{(2-r)^{2} i^{2}}{4 b}(1-\mathrm{t})$

$r\left(\pi_{\mathrm{h}}^{*}\right)=(1-r) \pi^{*}-\frac{1}{2} \frac{(2-r)^{2} i^{2}}{4 b} \mathrm{t}$

$r\left(\pi^{*}\right)=\mathrm{i} \frac{(2-r) i}{2 b}-\frac{1}{2} \frac{(2-r)^{2} i^{2}}{4 b}+\theta$

The sharing of the DOI cost undertaken by design enterprises can advance their enthusiam of optimization and innovation. When income sharing coefficient $r$ is determined, the optimum DOI cost sharing coefficient $t^{*}$ achieved, which is $\frac{2-3 r}{2-r}$, while $0<r<2 / 3$.

\section{CONCLUSIONS}

From the view of value chain analysis, the Stakeberg game model is applied, the green buildings' DOI incentive contract based on income/cost sharing of value chain is studied. The main conclusions are as follows:

The incentive subjects of green buildings' DOI consist of consumers, government and developers. Consumers and government have their effect on developers through market and policy mechanisms. Developers are the direct incentive subjects of DOI, whose incentive mechanism is contract mechanism.

The level of design enterprises' working effort determines the benefit of DOI, and the heart of their incentive contract planning is to properly determine the innovation allocation and cost sharing coefficient;

"Benchmark green building" index in the income sharing model as an observable reference variable is introduced in the design of incentive contract model, in order to reasonably confirm the income sharing coefficient and advance the level of design enterprises' working effort. The income sharing model analysis shows that, under non-cooperative game, the optimum sharing coefficient for design enterprises is $r^{*}=\mathrm{i}^{2} /\left[\mathrm{i}^{2}+\rho \mathrm{b}\left(\sigma^{2}-\frac{\operatorname{Cov}^{2}\left(\pi, \pi_{1}\right)}{\sigma_{1}^{2}}\right)\right]$, and its relationship with "benchmark green building" is $\gamma^{*}=$ $\frac{\operatorname{Cov}\left(\pi, \pi_{1}\right)}{\sigma_{1}^{2}}$

(4) The proper determination of DOI cost sharing coefficient will reduce the DOI cost of design enterprises, further sharing the risk of DOI. Studies show that: after the income sharing coefficient $r$ is confirmed, the optimum cost sharing coefficient $t^{*}$ is then obtained, which is $\frac{2-3 r}{2-r}$, with $0<r<\frac{2}{3}$. Meanwhile, the optimum level of working effort is $a$ ${ }^{*}=\frac{(2-r) i}{2 b}$, and the incremental income of value chain is $\pi^{*}=\mathrm{i} \frac{(2-r) i}{2 b}+\theta$.

\section{CONFLICT OF INTEREST}

The authors confirm that this article content has no conflict of interest.

\section{ACKNOWLEDGEMENTS}

This work was supported by the Science and Technology Project from Housing and Urban Construction Department, Jiang Shu, China. (Grant No.2011JH01)

\section{REFERENCES}

[1] Z. Ye, H. Li, and L. Song. Study on the Economics of Green Buildings in China. China Architecture \& Building Press, China, 2013.

[2] J. Wu, "Research on product value based on product lifecycle", thesis, Wuhan University of Technology, China, 2007.

[3] C. Pan, "The interpretation of industrial value chain-analyzing the fundamental characteristics of emerging industries' value Chain in China", Contemporary Finance \& Economics, vol. 9, pp. 7-15, 2001.

[4] C. Zhao, "Circular economy value chain model construction and performance appraisal", Commercial Research, no. 10, pp. 53-55, 2009.

[5] R. J. Cole, "Cost and value in building green", Building Research \& Information, vol. 28, pp. 304-309, 2000.

[6] Y Wang, "Research on industrial value chain theory and its application in Chinese VOIP industry", thesis, Harbin Institute of Technology, China, 2008.

[7] X. Liu, "Research on value-based cost control of the project in the design stage", thesis, Tianjin University of Technology, China, 2009.

[8] L. F. Matthiessen, and P. Morris, "Costing green: a comprehensive cost database and budgeting methodology", Davis Longdon: London, 2004.

[9] H. Wang, and C. Liu, "Incentive mechanism design based on game analysis for new building energy efficiency", Building Science, vol. 25 , no. 2 , pp. 24-28, 2009.

[10] L. W. Hong, "Pricing problem of Chinese construction products and research on the high value-added EPC mode for construction enterprises", Ph.D Thesis, Xian University of Architecture and Technology, China, 2010.

[11] J .Wu, K. Xie, and J. Xiao, Information Economics. Higher Education Press, Peking, 2007.

[12] Q. Tang, "Study on the establishment and related technology of agile virtual enterprise", $\mathrm{Ph}$. D. thesis, Tianjin University, China, 2002.

[13] J. Lu, and D. Pan, "Research on profit distribution of virtual enterprise based on technical exploitation item", Chinese Journal of Management Science, no. 5, pp.60-63, 2003. 
[14] F. Li, and B. Li, "Principal-agent model and incentive mechanism analysis", Quantitative \& Technical Economics, no. 9, pp. 29-33, 2003.

[15] L. Jean-Jacques, and M. David, The Theory of Incentives the Principal-Agent Model. China Renmin University Press, China, 2002.

[16] J. Gao, "Study on profit allocation of plant variety value chains", Ph. D. thesis, Shandong Agricultural University, China, 2012.
[17]

B. Hu, and X. Wang, "Supply chain revenue-sharing evolvementcontract with sales effects", Engineering Management, no. 2, pp. 135-188, 2010.

[18] X. Ji, "Study on design of supply chain contract under asymmetric producing cost information", Journal of Hunan University of Science and Technology, vol. 36, no. 6, pp. 1045-1048, 2006.

Received: July 28, 2013

Revised: August 11, 2013

Accepted: August 21, 2013

(c) Shen and Wang; Licensee Bentham Open.

This is an open access article licensed under the terms of the Creative Commons Attribution Non-Commercial License (http://creativecommons.org/licenses/ by-nc/3.0/) which permits unrestricted, non-commercial use, distribution and reproduction in any medium, provided the work is properly cited. 